\title{
Lithium ion conducting solid polymer blend electrolyte based on bio-degradable polymers
}

\author{
NATARAJAN RAJESWARI, SUBRAMANIAN SELVASEKARAPANDIAN",*,MONI PRABU, \\ SHUNMUGAVEL KARTHIKEYAN ${ }^{\dagger}$ and C SANJEEVIRAJA ${ }^{\ddagger}$ \\ Department of Physics, Kalasalingam University, Krishnankoil 626 126, India \\ †School of Advanced Sciences, VIT University, Vellore 632 014, India \\ ¥Department of Physics, Alagappa University, Karaikudi 630003 , India \\ \# Department of Nanosciences and Technology, Karunya University, Coimbatore 641 114, India
}

MS received 12 February 2012; revised 12 July 2012

\begin{abstract}
Lithium ion conducting polymer blend electrolyte films based on poly(vinyl alcohol) (PVA) and poly(vinyl pyrrolidone) (PVP) with different $\mathrm{Mwt} \%$ of lithium nitrate $\left(\mathrm{LiNO}_{3}\right)$ salt, using a solution cast technique, have been prepared. The polymer blend electrolyte has been characterized by XRD, FTIR, DSC and impedance analyses. The XRD study reveals the amorphous nature of the polymer electrolyte. The FTIR study confirms the complex formation between the polymer and salt. The shifts in $T_{\mathrm{g}}$ values of 70 PVA-30 PVP blend and 70 PVA30 PVP with different Mwt\% of $\mathrm{LiNO}_{3}$ electrolytes shown by DSC thermograms indicate an interaction between the polymer and the salt. The dependence of $T_{\mathrm{g}}$ and conductivity upon salt concentration has been discussed. The ion conductivity of the prepared polymer electrolyte has been found by a.c. impedance spectroscopic analysis. The PVA-PVP blend system with a composition of $70 \mathrm{wt} \%$ PVA: $30 \mathrm{wt} \%$ PVP exhibits the highest conductivity of $1.58 \times$ $10^{-6} \mathrm{Scm}^{-1}$ at room temperature. Polymer samples of $70 \mathrm{wt} \%$ PVA-30 wt\% PVP blend with different molecular weight percentage of lithium nitrate with DMSO as solvent have been prepared and studied. High conductivity of $6.828 \times 10^{-4} \mathrm{Scm}^{-1}$ has been observed for the composition of 70 PVA:30 PVP:25 Mwt $\%$ of $\mathrm{LiNO}_{3}$ with low activation energy $0.2673 \mathrm{eV}$. The conductivity is found to increase with increase in temperature. The temperature dependent conductivity of the polymer electrolyte follows the Arrhenius relationship which shows hopping of ions in the polymer matrix. The relaxation parameters $(\omega)$ and $(\tau)$ of the complexes have been calculated by using loss tangent spectra. The mechanical properties of polymer blend electrolyte such as tensile strength, elongation and degree of swelling have been measured and the results are presented.
\end{abstract}

Keywords. PVA-PVP; polymer blend; Li ion; XRD; FTIR; impedance analysis.

\section{Introduction}

In recent years Li-ion battery is one of the most important power sources because of its higher energy density, shape and design flexibility, lower-self discharge rate, no memory effect and longer life span compare to other secondary battery (Amatucci and Tarascon 2002). The ion-exchange membrane plays an important role in electrochemical devices. The main advantages of polymeric electrolytes are their mechanical properties, ease of fabrication of thin films of desired sizes and their ability to form proper electrode-electrolyte contact.

Many approaches have been adopted to enhance their conductivity to a reasonable value suitable for applications. This includes the addition of plasticizers, use of copolymers, addition of inert insulating matrix of nanosize, use of salt with large anions and blending of two polymers (Cherng et al 1988; Armand et al 1990; Covpuano et al 1991; Benrabah

\footnotetext{
*Author for correspondence (sekarapandian@ rediffmail.com)
}

et al 1993; Wieczorek and Stevens 1997; Wen et al 2003). Polymer blend is most promising and feasible approach because of ease of preparation and easy control of physical properties within the polymer compositions. Over $30 \%$ of commercial polymers used worldwide are polymer blends (Utracki 1990). The polymer blends are useful in a variety of high performance applications such as drug delivery, tissue engineering and permeable membranes for separation technology (Todd et al 2005).

The presence of hydroxyl and carbonyl group in the structure of PVA and PVP acts as an electron pair donor that enable complexation with lithium ions. Moreover PVA and PVP have good film forming properties, cheap, non-toxic and biodegradable. PVA is semicrystalline polymer and its crystalline nature is decreased by the addition of amorphous nature PVP. Both PVA and PVP are soluble in DMSO and form high-degree complexes with large variety of dopant.

In the present work, the structural, vibrational, mechanical and electrical properties of 70 PVA:30 PVP blend with different molecular weight percentage of $\mathrm{LiNO}_{3}$ have been presented. 


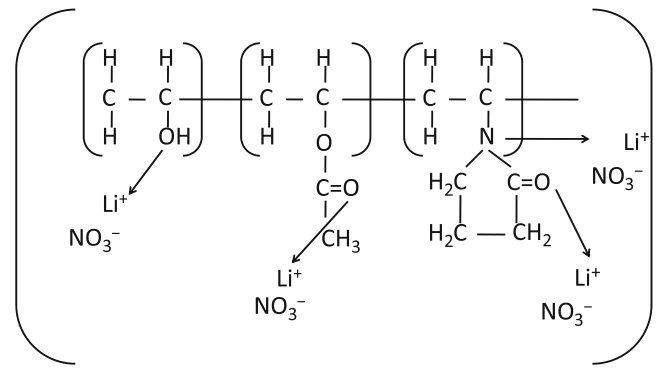

Scheme 1. Possible interaction between polymer and salt.

\section{Experimental}

Polymers poly(vinyl alcohol) (PVA) with molecular weight of 1,25,000, poly(vinyl pyrrolidone) (PVP) with molecular weight of 90,000 and salt lithium nitrate $\left(\mathrm{LiNO}_{3}\right)$ are used as raw materials. DMSO has been used as solvent. Solid polymer blend electrolytes studied in the present work are prepared by the solution casting method.

Stoichiometric quantities of PVA, PVP and $\mathrm{LiNO}_{3}$ are dissolved in DMSO and then stirred until homogeneous solution is obtained and the final solution is poured into polypropylene dishes and dried in an oven at $70^{\circ} \mathrm{C}$ for 6 days to ensure removal of solvent traces.

The smooth, uniform thin films which are transparent to visible light with good mechanical properties have been obtained. The obtained films are kept in a desiccator for further drying and then used for different experimental studies. The thickness of the samples has been found to be in the range of $0 \cdot 156-0.416 \mathrm{~mm}$.

The X-ray diffraction pattern of polymer electrolytes has been recorded using $\operatorname{CuK}_{\alpha}(\lambda=1.5406 \AA)$ radiation. The IR spectrum has been recorded for polymer electrolytes in the range of $400-4000 \mathrm{~cm}^{-1}$ at room temperature using SHIMADZU IR affinity-1 spectrometer. Thermal stability of the electrolytes has been studied using SII EXSTAR 6000 system. The samples are put in an $\mathrm{Al}$ pan and heated from $20^{\circ} \mathrm{C}$ up to $160^{\circ} \mathrm{C}$ at the rate of $10^{\circ} \mathrm{C} / \mathrm{min}$. The ion conductivity study of the polymer electrolytes has been carried out in the temperature range of $303-373 \mathrm{~K}$ over a frequency range of $42 \mathrm{~Hz}-1 \mathrm{MHz}$ using a computer controlled HIOKI 3532 LCR meter. Tensile strength and elongation of polymer blend electrolyte have been evaluated by using INSTRON 4240 testing machine. The complexation of the lithium nitrate with PVA-PVP blend polymer has been shown in scheme 1.

\section{Results and discussion}

\subsection{XRD analysis}

Figure $1(\mathrm{a}-\mathrm{f})$ show that the $\mathrm{X}$-ray diffraction pattern of pure 70 PVA:30 PVP blend and 70 PVA-30 PVP blend with different $\mathrm{Mwt} \%$ of $\mathrm{LiNO}_{3}$. Figure 1(a-f) shows peak intensity

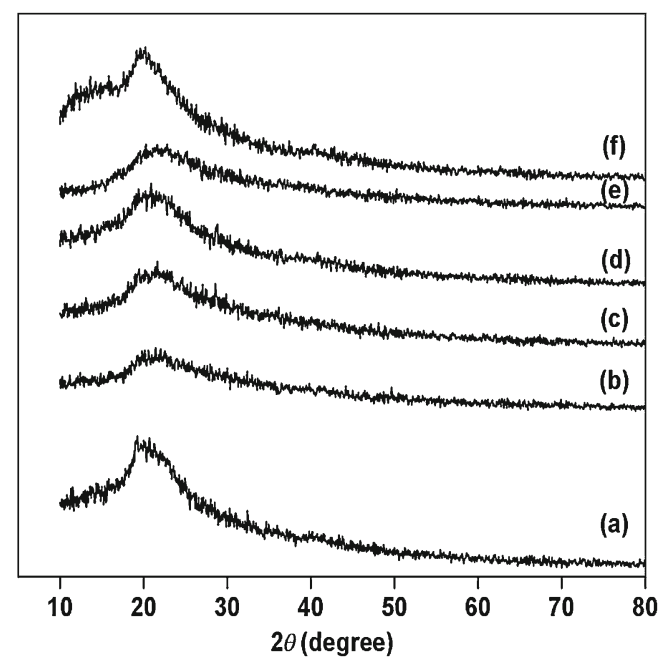

Figure 1. XRD pattern of (a) 70 PVA:30 PVP, (b) 70 PVA: 30 PVP:10 Mwt $\% \mathrm{LiNO}_{3}$, (c) 70 PVA:30 PVP:15 Mwt\% $\mathrm{LiNO}_{3}$, (d) 70 PVA:30 PVP:20 Mwt $\% \mathrm{LiNO}_{3}$, (e) 70 PVA: 30 PVP: $25 \mathrm{Mwt} \% \mathrm{LiNO}_{3}$ and (f) 70 PVA:30 PVP:30 Mwt $\% \mathrm{LiNO}_{3}$.

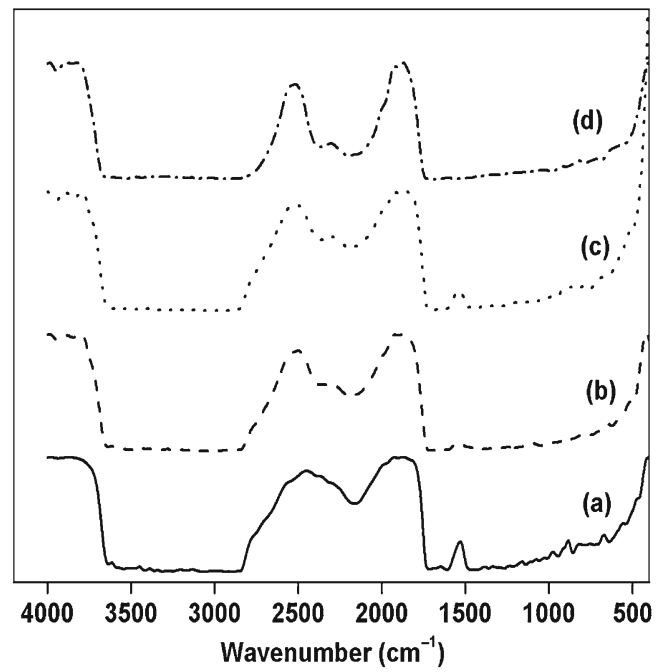

Figure 2. FTIR pattern of (a) 70 PVA:30 PVP, (b) 70 PVA: 30 PVP:20 Mwt $\% \mathrm{LiNO}_{3}$, (c) 70 PVA:30 PVP:25 Mwt\% $\mathrm{LiNO}_{3}$ and (d) 70 PVA:30 PVP:30 Mwt\% $\mathrm{LiNO}_{3}$.

at $2 \theta=20^{\circ}$ for pure PVA. The above peak gets decreased with increasing concentration of $\mathrm{LiNO}_{3}$ which implies decrease of degree of crystallization and increase of amorphous nature.

Hodge et al (1996) established a correlation between intensity of the peak and degree of crystallinity. None of the diffraction peak pertaining to $\mathrm{LiNO}_{3}$ is observed indicating that the salt is completely dissociated. The highest amorphous nature is observed for the sample 70 PVA:30 PVP: $25 \mathrm{Mwt} \%$ of $\mathrm{LiNO}_{3}$ (figure 1e). 


\subsection{FTIR analysis}

The IR spectra of pure 70 PVA:30 PVP and 70 PVA:30 PVP blend with different $\mathrm{Mwt} \%$ of $\mathrm{LiNO}_{3}$ are shown in figure 2. From figure 2, the observed band around $3070 \mathrm{~cm}^{-1}$ has been attributed to $\mathrm{C}-\mathrm{H}$ stretching of pure PVA; the above peak gets shifted when the salt concentration has been increased. The band corresponding to $\mathrm{C}-\mathrm{N}$ stretching observed at $2174 \mathrm{~cm}^{-1}$ for pure PVP has been shifted to 2188$2174 \mathrm{~cm}^{-1}$ for 70 PVA:30 PVP with different concentration of $\mathrm{LiNO}_{3}$ polymer blend electrolytes with variation in intensity. The shift in stretching modes of the carbonyl bonds due to pyrrolidone rings are seen from peaks in the region 1623$1693 \mathrm{~cm}^{-1}$. The vibrational bands at about $861 \mathrm{~cm}^{-1}$ corresponding to $\mathrm{C}-\mathrm{H}$ rocking of PVA has been shifted to $832-$ $843 \mathrm{~cm}^{-1}$. The observed shifts and variation in intensities of the FTIR spectrum of the blend suggest that the complete complexation of salt with polymer blends.

\subsection{DSC analysis}

The DSC curve of 70 PVA:30 PVP and 70 PVA:30 PVP blend with different $\mathrm{Mwt} \%$ of $\mathrm{LiNO}_{3}$ are shown in figure 3(a) and glass transition temperatures are given in table 1 . The thermal properties of PVA and PVP blend and their complexes have been examined by DSC. The glass transition temperature of the semicrystalline PVA polymer is $70^{\circ} \mathrm{C}$ and PVP is $160^{\circ} \mathrm{C}$. The $T_{\mathrm{g}}$ values of the PVA-PVP blend may lie between 70 and $160^{\circ} \mathrm{C}$ (Vasile Cristian Grigoras and Virgil Barboiu 2008). The exothermic peak at about $69^{\circ} \mathrm{C}$ for pure PVA-PVP blend could be due to a small amount of moisture, which is present in the conventional sample unless it is carefully vacuum dried. An endothermic peak observed at around $130^{\circ} \mathrm{C}$ corresponds to the glass transition temperature of PVA-PVP blend. The addition of lithium nitrate to

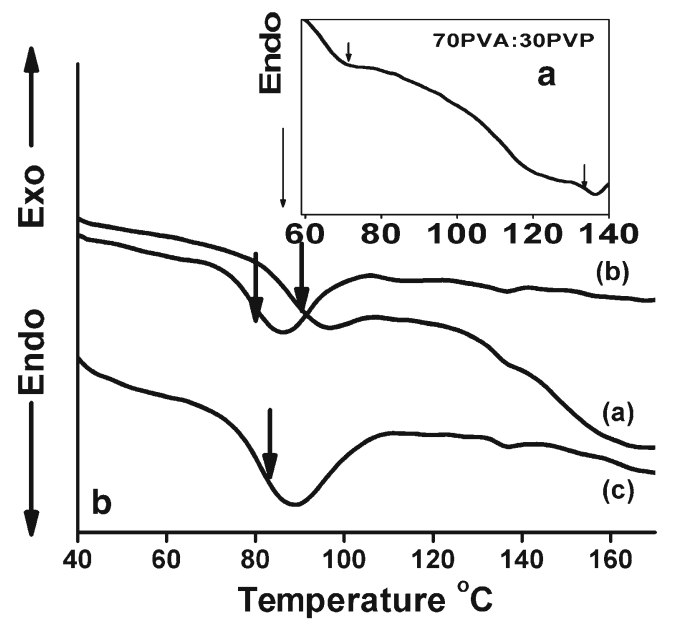

Figure 3. DSC curve of 70 PVA-30 PVP polymer blend electrolyte. DSC curves of (a) 70 PVA:30 PVP:20 Mwt\% $\mathrm{LiNO}_{3}$, (b) 70 PVA:30 PVP:25 Mwt $\% \mathrm{LiNO}_{3}$ and (c) 70 PVA:30 PVP: $30 \mathrm{Mwt} \% \mathrm{LiNO}_{3}$.
PVA and PVP blend decreases the glass transition temperature of polymer blend from 130 to $89^{\circ} \mathrm{C}, 80$ and $82^{\circ} \mathrm{C}$ for 15 , 25 and $30 \mathrm{Mwt} \%$ of $\mathrm{LiNO}_{3}$, respectively. The $T_{\mathrm{g}}$ decreases with increasing $\mathrm{LiNO}_{3}$ concentration. This can be interpreted on the basis of chain flexibility which is reflected by $T_{\mathrm{g}}$. This decrease in $T_{\mathrm{g}}$ may be attributed to the plasticizing effect. The low glass transition temperature causes higher segmental motion of the polymer electrolyte.

\subsection{AC impedance analysis}

The ion conductivity of the solid polymer blend (70 PVA: 30 PVP:LiNO 3 ) system has been derived from the complex impedance plots. The impedance spectra of 70 PVA:30 PVP blend doped with different composition of $\mathrm{LiNO}_{3}$ is shown in figure 4 . The inset of figure 4 shows the Cole-Cole plot of 70 PVA:30 PVP blend with 20, 25 and $30 \mathrm{Mwt} \%$ of $\mathrm{LiNO}_{3}$. The spectra consist of two regions, a depressed semicircle at high frequency representing the parallel combination of bulk resistance and capacitance which is due to the bulk effect of the electrolytes and the linear region which in the lowfrequency range is attributed to the effect of blocking electrodes. From figure 4, it has been noted that the semicircle decreases with the increase in the salt concentration. This

Table 1. Glass transition temperatures of 70 PVA:30 PVP and 70 PVA:30 PVP blends with different concentrations of $\mathrm{LiNO}_{3}$.

\begin{tabular}{lc} 
Composition & $\begin{array}{c}\text { Glass transition temperature, } \\
T_{\mathrm{g}}\left({ }^{\circ} \mathrm{C}\right)\end{array}$ \\
\hline 70 PVA:30 PVP & 130 \\
70 PVA:30 PVP:15 Mwt\% $\mathrm{LiNO}_{3}$ & 89 \\
70 PVA:30 PVP:25 Mwt\% $\mathrm{LiNO}_{3}$ & 80 \\
70 PVA:30 PVP:30 Mwt\% LiNO & 82 \\
\hline
\end{tabular}

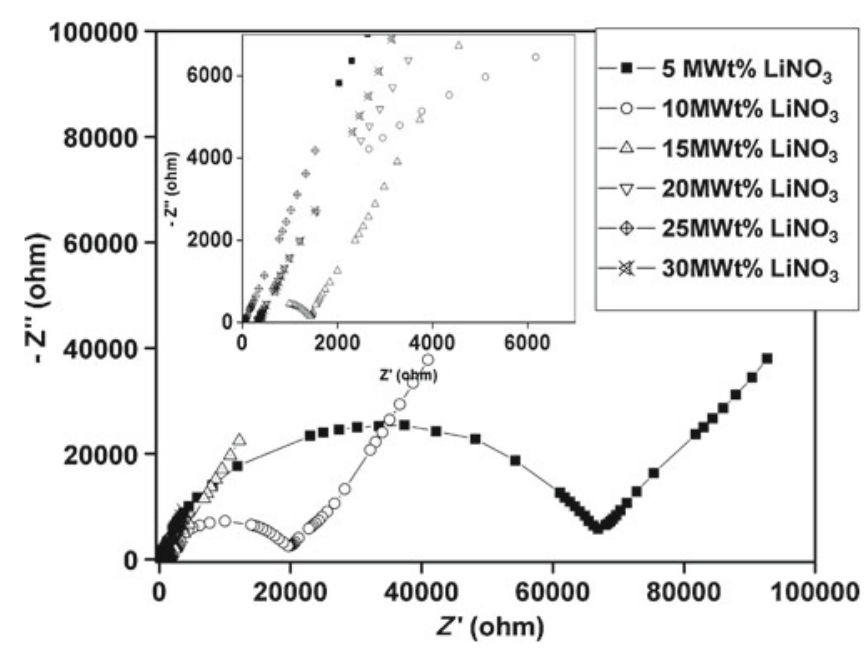

Figure 4. Cole-Cole plot for 70 PVA:30 PVP blend with different concentrations of $\mathrm{LiNO}_{3}$ at room temperature. 
Table 2. Conductivity $(\sigma)$ and relaxation frequency values of $70 \mathrm{PVA}: 30 \mathrm{PVP}$ with different concentrations of $\mathrm{LiNO}_{3}$ at room temperature.

\begin{tabular}{|c|c|c|c|}
\hline Composition & Conductivity $\left(\mathrm{Scm}^{-1}\right)$ & Angular frequency $\left(\omega_{\max }\right)$ & Relaxation frequency, $\tau(\mathrm{s})$ \\
\hline 70 PVA:30 PVP:5 Mwt $\% \mathrm{LiNO}_{3}$ & $6 \cdot 266 \times 10^{-7}$ & $12302 \cdot 68771$ & $8 \cdot 12 \times 10^{-5}$ \\
\hline 70 PVA:30 PVP:10 Mwt $\% \mathrm{LiNO}_{3}$ & $1.443 \times 10^{-6}$ & $47533 \cdot 52259$ & $2.10 \times 10^{-6}$ \\
\hline 70 PVA:30 PVP:15 Mwt $\% \mathrm{LiNO}_{3}$ & $1.089 \times 10^{-5}$ & $438833 \cdot 7287$ & $2.27 \times 10^{-6}$ \\
\hline 70 PVA:30 PVP:20 Mwt $\% \mathrm{LiNO}_{3}$ & $9.225 \times 10^{-5}$ & $1270866 \cdot 699$ & $7.86 \times 10^{-7}$ \\
\hline 70 PVA:30 PVP:25 Mwt\% $\mathrm{LiNO}_{3}$ & $6.828 \times 10^{-4}$ & $2884031 \cdot 503$ & $3.46 \times 10^{-7}$ \\
\hline 70 PVA:30 PVP:30 Mwt $\% \mathrm{LiNO}_{3}$ & $9.917 \times 10^{-5}$ & $1914696 \cdot 749$ & $5 \cdot 22 \times 10^{-7}$ \\
\hline
\end{tabular}

result suggests that only the resistive component of polymer electrolyte prevails when the concentration is increased. The capacitive nature disappears due to random orientation of the dipoles in the side chains (Ramya et al 2006).

The EQ software program developed by Boukamp (1986) has been used to extract the bulk electrical resistance $\left(R_{\mathrm{b}}\right)$ of the polymer blend electrolytes from the impedance plot of the low frequency side intercept on the $Z^{\prime}$ axis. The ion conductivity is calculated using the equation

$$
\sigma=L / R_{\mathrm{b}} A
$$

where $L$ is the thickness of the polymer blend electrolyte and $A$ the surface area of the polymer blend electrolyte.

The conductivity values for all the compositions of 70 PVA:30 PVP:LiNO 3 polymer electrolytes at room temperature have been presented in table 2 . The highest room temperature conductivity value is found to be $6.828 \times 10^{-4}$ $\mathrm{Scm}^{-1}$ for the composition of 70 PVA:30 PVP:25 Mwt\% of $\mathrm{LiNO}_{3}$. The low glass transition temperature has been observed for this high conductivity composition.

\subsection{Conductance spectra analysis}

The logarithmic plot of the variation of conductivity as a function of the angular frequency for the 70 PVA:30 PVP blend with different composition of $\mathrm{LiNO}_{3}$ polymer blend electrolyte complex at $303 \mathrm{~K}$ is shown in figure 5 . The plots show three well-defined regions, a low frequency dispersion region relating to the blocking of ions between the electrodes and the electrolyte, frequency independent plateau region in the mid frequency when is related to the bulk conductivity and dispersion at the high frequency obeying the power law $A \omega^{n}$.

The conductivity $\sigma(\omega)$ obeys the Jonscher's power law (Jonscher 1977) and it is found to vary with angular frequency $\omega$.

$$
\sigma(\omega)=\sigma_{\text {d.c. }}+A \omega^{n} .
$$

Where $\sigma_{\text {d.c. }}$ is the d.c. conductivity, $A$ and $n$ are temperature dependent parameters. The d.c. conductivity values have been calculated by the extrapolation of the plateau

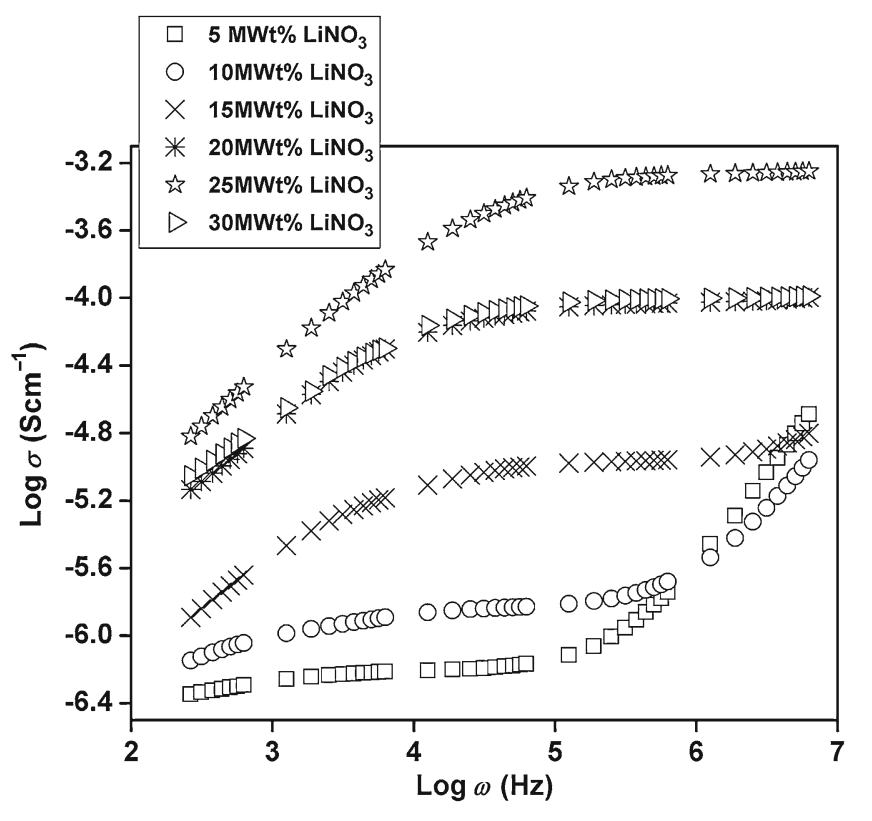

Figure 5. Conductance spectra for 70 PVA:30 PVP blend with different concentrations of $\mathrm{LiNO}_{3}$ at room temperature.

region to zero frequency. The highest conductivity $6.82 \times$ $10^{-4} \mathrm{Scm}^{-1}$ has been observed for the composition of 70 PVA:30 PVP:25 Mwt\% $\mathrm{LiNO}_{3}$.

\subsection{Concentration dependence conductivity}

The variation of room temperature d.c. conductivity $\left(\sigma_{\text {d.c. }}\right)$ as a function of different Mwt $\%$ of lithium nitrate has been given in figure 6 . The conductivity of pure (70 PVA:30 PVP) has been found to be of the order of $1.58 \times 10^{-6} \mathrm{Scm}^{-1}$ at room temperature. This result is already reported by Rajeswari et al (2011). Figure 6 clearly shows that the conductivity increases with increase in $\mathrm{LiNO}_{3}$ concentration up to $25 \mathrm{Mwt} \% \mathrm{LiNO}_{3}$. This may be due to increase in the number of mobile charge carriers and also to the increase in the amorphous nature of the polymer electrolyte which reduces the energy barrier there by facilitating the ion transport. However, a decrease in conductivity is observed for the 


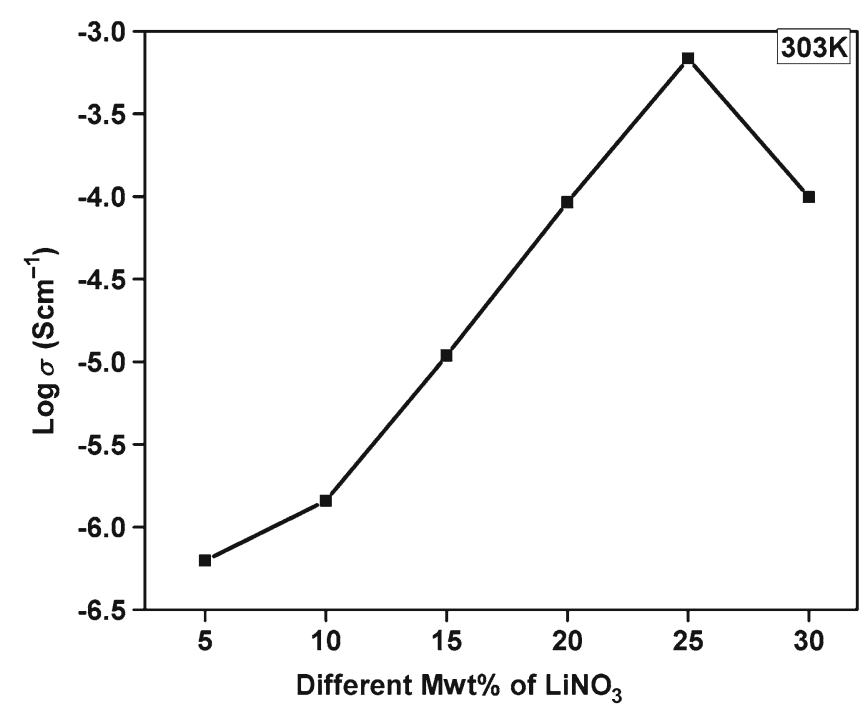

Figure 6. Salt concentration vs $\log \sigma$ for all compositions at room temperature.

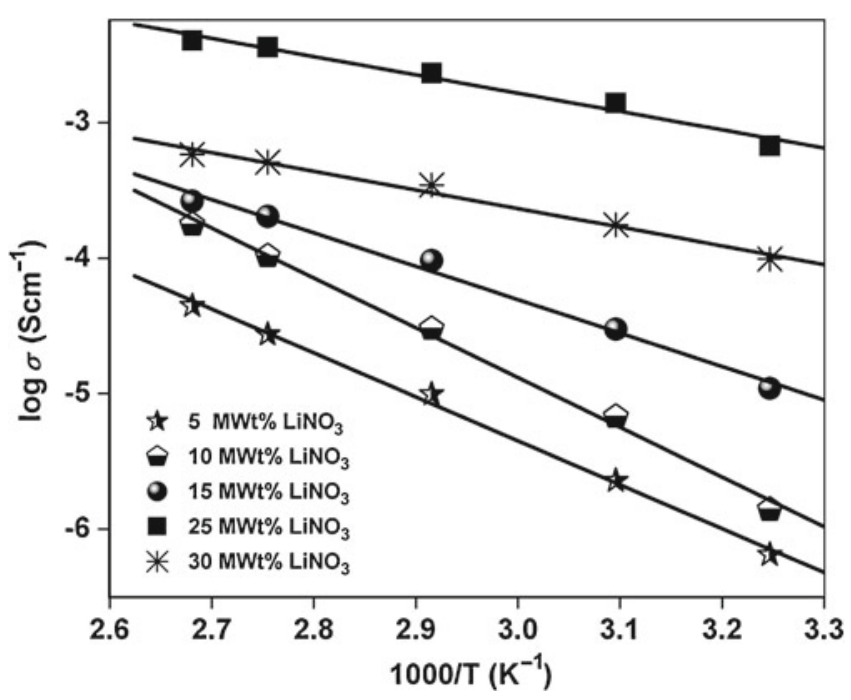

Figure 7. $1000 / T$ vs $\log \sigma$ for 70 PVA:30 PVP polymer blend with different concentrations of $\mathrm{LiNO}_{3}$.

composition of $30 \mathrm{Mwt} \%$ of $\mathrm{LiNO}_{3}$ doped with PVA and PVP. This may be due to the aggregation of ions, leading to decreasing the number of mobile charge carriers and hence the mobility (Ramya et al 2007). The highest ion conductivity $6.82 \times 10^{-4} \mathrm{Scm}^{-1}$ has been observed for the composition of 70 PVA:30 PVP:25 Mwt\% $\mathrm{LiNO}_{3}$.

\subsection{Temperature dependence conductivity}

Figure 7 shows the variation of ion conductivity with the reciprocal of temperature for 70 PVA:30 PVP blend with different $\mathrm{Mwt} \%$ of $\mathrm{LiNO}_{3}$. The linear variation of $\sigma$ vs 1000/T
Table 3. The activation energy and regression value for 70 PVA: 30 PVP blend with different concentrations of $\mathrm{LiNO}_{3}$.

\begin{tabular}{llc}
\hline Composition & $\begin{array}{c}\text { Activation energy, } \\
E_{\mathrm{a}}(\mathrm{eV})\end{array}$ & $\begin{array}{c}\text { Regression } \\
\text { value, } R\end{array}$ \\
\hline 70 PVA:30 PVP:5 Mwt\% LiNO & 0.642 & 0.99 \\
70 PVA:30 PVP:10 Mwt\% & 0.728 & 0.99 \\
70 PVA:30 PVP:15 Mwt\% $\mathrm{LiNO}_{3}$ & 0.4885 & 0.99 \\
70 PVA:30 PVP:25 Mwt\% $\mathrm{LiNO}_{3}$ & 0.2673 & 0.98 \\
70 PVA:30 PVP:30 Mwt\% LiNO & 0.2728 & 0.99 \\
\hline
\end{tabular}

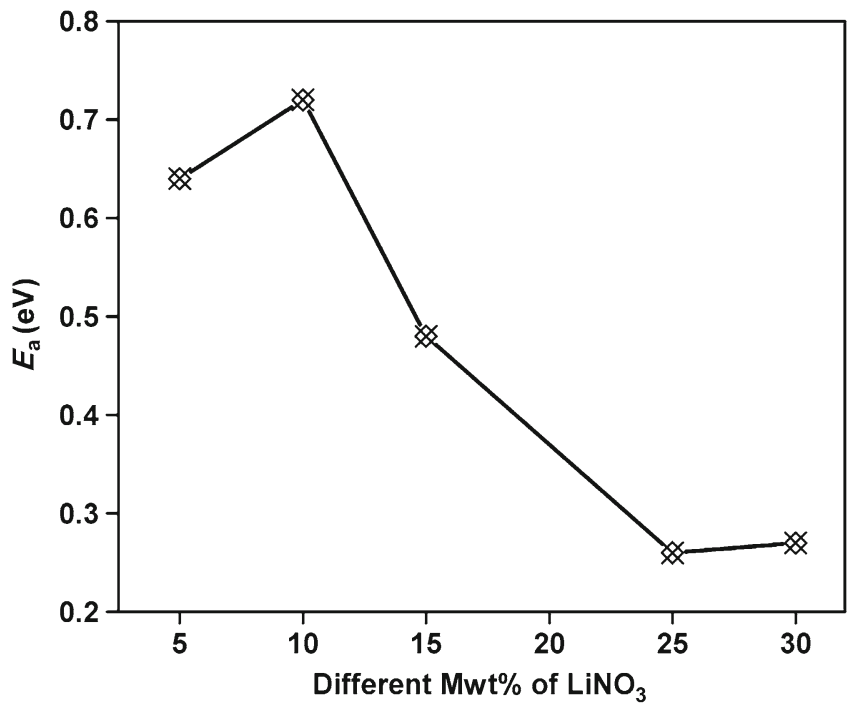

Figure 8. Salt concentration vs activation energy for all compositions.

plots suggests a thermally activated process. The conductivity can be expressed as

$$
\sigma T=\sigma_{0} \exp \left(-E_{\mathrm{a}} / K T\right),
$$

where $\sigma_{0}$ is the pre-exponential factor, $E_{\mathrm{a}}$ the activation energy and $T$ the absolute temperature. From figure 7, it has been found that the conductivity of the blend polymer electrolyte increases with increasing temperature. This suggests that the number of complex sites increases with temperature (Archer and Armstrong 1995). This enables $\mathrm{Li}^{+}$ to move from one transit site to another without having acquired much energy. The activation energy for $\mathrm{Li}^{+}$ion transport calculated from the slope of the plot based on (1) is significantly low $(0.2673 \mathrm{eV})$ for the composition of 70 PVA:30 PVP:25 Mwt\% $\mathrm{LiNO}_{3}$ and tabulated in table 3. The regression value is close to unity for the graph suggesting that all the points lie on a straight line.

Figure 8 shows that when the concentration of $\mathrm{LiNO}_{3}$ increases it can be noticed that $E_{\mathrm{a}}$ decreases, indicating that the $\mathrm{Li}^{+}$ions to migrate from one site to another site require lower energy. The high conductivity with low activation energy is observed for 70 PVA:30 PVP:25 Mwt\% $\mathrm{LiNO}_{3}$. 
The $E_{\mathrm{a}}$ is found to be low in the order of $0.2673 \mathrm{eV}$ for the high conductivity sample.

\subsection{Loss tangent spectra}

The dependence of the dielectric loss tangent $(\tan \delta$ ) on frequency under different concentrations of $\mathrm{LiNO}_{3}$ is shown in figure 9 . From figure 9 it is clearly shows that the $\tan \delta$ value increases with increasing frequency and salt concentration at room temperature, and it passes through a maximum value and thereafter decreases. The absorption peak is described by the relation

$$
\omega \tau=1,
$$

where $\tau$ is the relaxation time of the hopping process and $\omega$ the angular frequency of the external field

$$
\omega=2 \Pi f_{\max } ; \quad \tau=1 / \omega .
$$

The $\tau$ values have been calculated and tabulated in table 2 . The peak maximum shift (figure 9) towards high frequency with increasing salt concentration which indicates that the jumping probability per unit time increases with increasing concentration. The dispersion observed at low frequencies could be attributed to the interfacial-polarization mechanism. The height of the peak increases with increasing concentration which is due to the increment in number of charge carriers for conduction (Dieterich and Maass 2002).

\subsection{Mechanical property}

Tensile strength (TS) and elongation (\%E) have been evaluated for each film using an INSTRON 4240 testing machine.

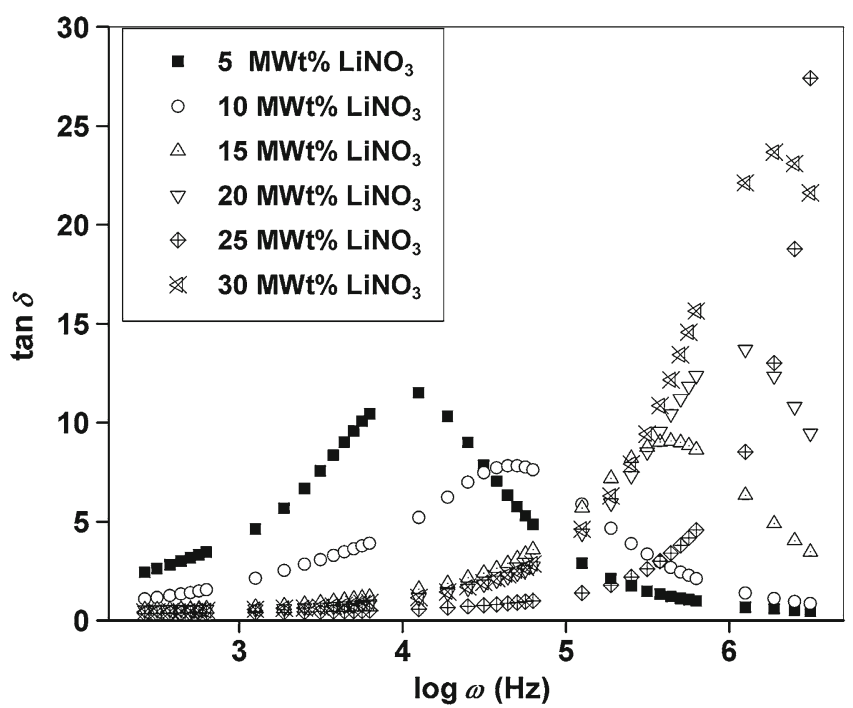

Figure 9. $\tan \delta$ vs $\log$ frequency for different compositions of 70 PVA:30 PVP complexed $\mathrm{LiNO}_{3}$ polymer electrolyte at room temperature.
Two plate-shaped specimens (ASTM-638) were cut from each film. Specimens had a width of $6.5 \mathrm{~mm}$ and $\sim 1 \mathrm{~mm}$ thickness. The gauge length is $25 \mathrm{~mm}$. Figures 10(a) and (b) show the tensile strength and elongation of polymer blend electrolyte for different compositions of PVA:PVP (60:40, 70:30). It is clear from figures $10(a-b)$, the composition of 70 PVA:30 PVP bear maximum load compared to other compositions. This composition could bear a maximum load $30.0625 \mathrm{~N}$ with an extension $375.938 \%$ and tensile strength $5.64024 \mathrm{MPa}$.

3.9a Degree of swelling of polymer blend electrolyte: Dried PVA:PVP blend and 70 PVA:30 PVP:25 Mwt $\% \mathrm{LiNO}_{3}$ polymer blend electrolyte have been immersed in distilled water at room temperature. After some stable time, moisture on the surface of the film has been removed and the weight of
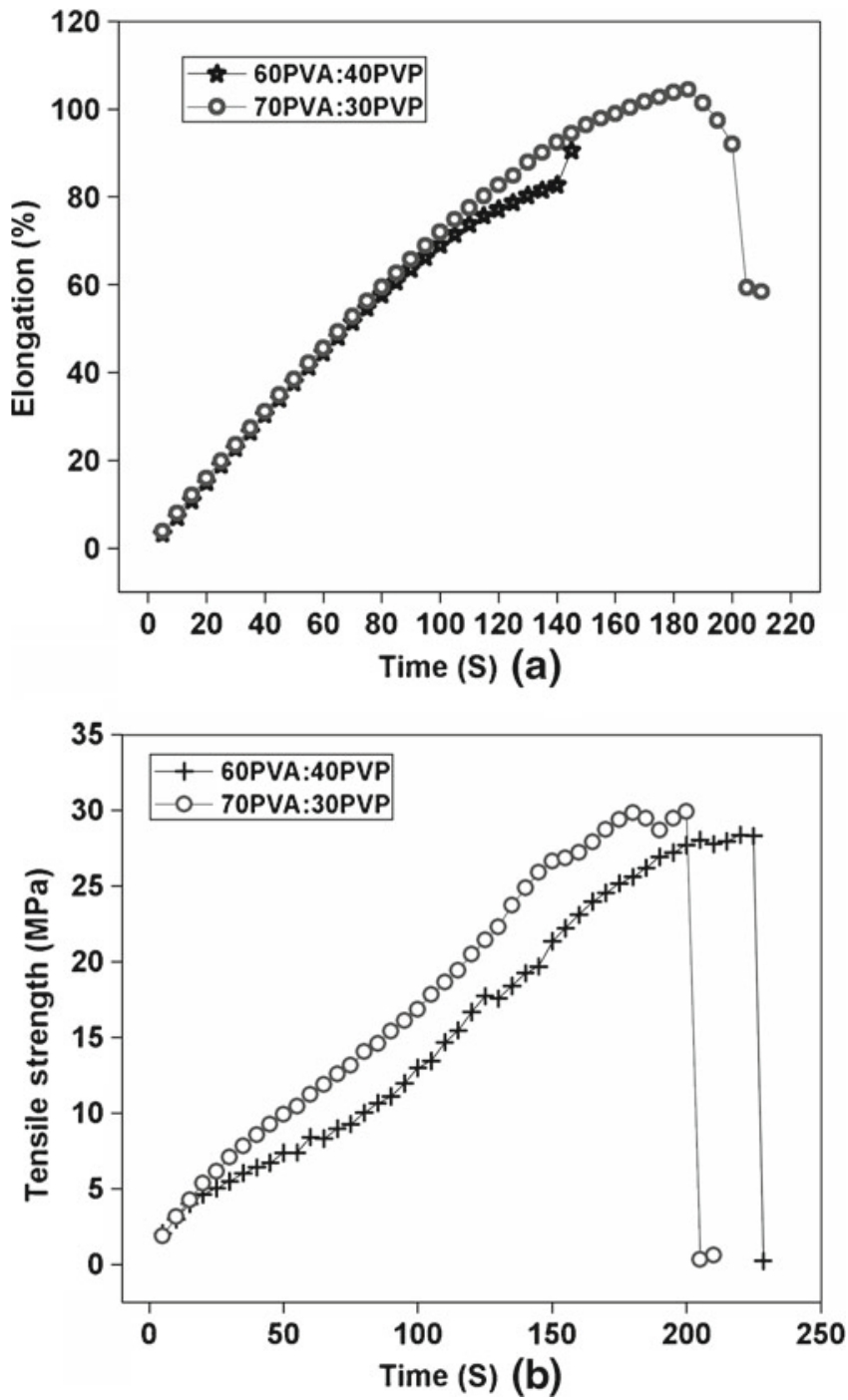

Figure 10. (a)-(b) Elongation and tensile strength of different compositions of PVA: PVP. 


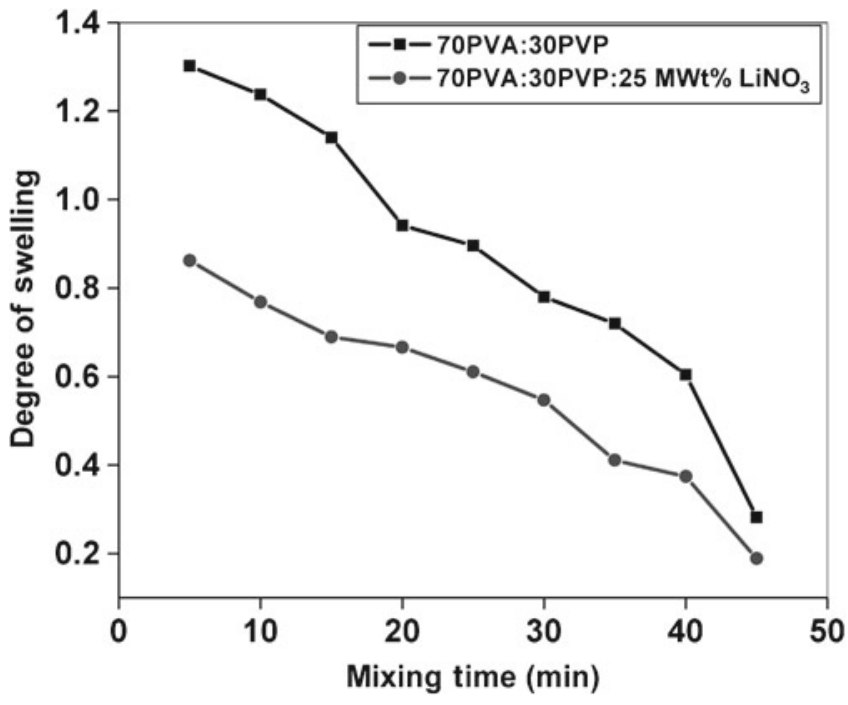

Figure 11. Mixing time vs degree of swelling of 70 PVA:30 PVP and 70 PVA:25 Mwt\% $\mathrm{LiNO}_{3}$ polymer blend electrolyte.

the films is measured. Degree of swelling has been calculated by the equation

$$
D S=\left(W_{\mathrm{e}}-W_{\mathrm{o}}\right) / W_{\mathrm{o}},
$$

where $W_{\mathrm{e}}$ is the weight of the polymer blend electrolytes at the adsorbing equilibrium and $W_{\mathrm{o}}$ the first dry weight of polymer blend electrolyte. Figure 11 shows that the degree of swelling of 70 PVA:30 PVP and 70 PVA:30 PVP:25 Mwt\% $\mathrm{LiNO}_{3}$ polymer blend electrolyte. From the figure it is observed that the DS has decreased rapidly with increase of immersing time. Degree of swelling value of PVA:PVP blend with $\mathrm{LiNO}_{3}$ film is lower than 70 PVA:30 PVP blend, it may be due to the lithium salt.

\section{Conclusions}

PVA- and PVP- based lithium ion conducting polymer electrolytes with lithium nitrate in different molecular weight percentage have been prepared by solution casting technique using DMSO as solvent. The XRD analysis reveals the increase in amorphous nature of the polymer electrolytes.
The FTIR provides an evidence for the existence of an interaction between $\mathrm{Li}^{+}$ion and polymer thereby revealing the complexation in the prepared polymer electrolytes. From the conductivity analysis the highest conductivity at room temperature has been found to be $6.82 \times 10^{-4} \mathrm{Scm}^{-1}$ for the composition of 70 PVA:30 PVP:25 Mwt $\% \mathrm{LiNO}_{3}$. The activation energy of the high conductivity sample is calculated using the Arrhenius plot and it has been found to be $0 \cdot 2 \mathrm{eV}$. The relaxation frequency complexes have been calculated by using loss tangent spectra.

\section{References}

Amatucci G and Tarascon J M 2002 J. Electrochem. Soc. 149 K31

Archer W L and Armstrong R D 1995 Electrochim. Acta 99140 Armand M, Gorecki W and Andreani R 1990 in Second int. symp. polymer electrolytes (ed.) B Scrosati (London: Elsevier) p. 91

Benrabah D, Bard D, Sanchez J Y, Armand M and Gard G G 1993 J. Chem. Soc. Faraday Trans. 35589

Boukamp B A 1986 Solid State Ionics 20301

Cherng J Y, Munshi M Z A, Owens B B and Smyrl W H 1988 Solid State Ionics $\mathbf{8 5 7} 28$

Covpuano F, Croce F and Scrosati B 1991 J. Electrochem. Soc. 1918 138

Dieterich W and Maass P 2002 Chem. Phys. 284439

Hodge R M, Edward G H and Simon G P 1996 Polymer 137137

Jonscher A K 1977 Nature 267673

Rajeswari N, Selvasekarapandian S, Karthikeyan S, Prabu M, Hirankumar G, Nithya H and Sanjeeviraja C 2011 J. Non-Crystal. Solids $\mathbf{3 7 5 1} 357$

Ramya C S, Selvasekarapandian S, Savitha T, Hirankumar G and Angelo P C 2006 Eur. Polym. J. 422672

Ramya C S, Selvasekarapandian S, Savitha T and Hirankumar G 2007 Physica B 39311

Todd Alam M, Joshua Otaigbe U, Dave Rhoades, Gregory P Holland, Brian R Cherry and Paul G Kotula 2005 Polymer 46 12468

Utracki L A 1990 Polymer alloys and blends (Munich: Hanser)

Vasile Cristian Grigoras and Virgil Barboiu 2008 Revue Roumanine de Chimie 53(2) 127

Wen Z, Itoh T, Uno T, Kubo M and Yamamoto O 2003 Solid State Ionics 160141

Wieczorek W and Stevens J R 1997 J. Phys. Chem. Solids B1529 101 